\title{
APPLYING THE APOS THEORY TO IMPROVE STUDENTS ABILITY TO PROVE IN ELEMENTARY ABSTRACT ALGEBRA
}

\author{
I M. Arnawa, U. Sumarno, B. Kartasasmita, \\ AND E.T. BASKORO
}

\begin{abstract}
This study is a quasi-experimental nonrandomized pretest-posttest control group design. The experiment group is treated by APOS theory instruction (APOS), that implements four characteristics of APOS theory, (1) mathematical knowledge was constructed through mental construction: actions, processes, objects, and organizing these in schemas, (2) using computer, (3) using cooperative learning groups, and (4) using ACE teaching cycle (activities, class discussion, and exercise). The control group is treated by conventional/traditional mathematics instruction (TRAD). The main purpose of this study is to analyze about achievement in proof. 180 students from two different universities (two classes at the Department of Mathematics UNAND and two classes at the Department of Mathematics Education UNP PADANG) were engaged as the research subjects. Based on the result of data analysis, the main result of this study is that the proof ability of students' in the APOS group is significantly better than student in TRAD group, so it is strongly suggested to apply APOS theory in Abstract Algebra course.
\end{abstract}

\section{INTRODUCTION}

Proof is an essential characteristic of mathematics and as such should be a key component in mathematics education $([10,13,20])$, that has been considered as a fundamental part of mathematical endeavor since ancient times [14]. According to Reid in [19], it makes mathematics different from all other areas of human activity. Proof is most valuable when it leads to understanding and help in thinking more clearly and effectively about mathematics. Understanding as a fundamental aspect of education (see [19]) is considered to be ultimate outcome toward which all learning and teaching processes in mathematics education are directed [12]. Thus,

Received 13 June 2006, revised 2 December 2006, accepted 28 December 2006.

2000 Mathematics Subject Classification: 97D40

Key words and Phrases: proof ability, abstract algebra, APOS theory. 
above all, the purpose of teaching and learning proof is to promote understanding [10].

Despite its importance, proof has been known difficult to teach and learn. Research indicates that students at both high school and university level have difficulties, not only in producing proof, but also even in recognizing what a proof is. Moore [18] found seven major sources of student difficulties in learning to do proofs, including inability to state the definition, inadequate concepts image, inability to use the definition to structure a proof, inability or unwillingness to generate examples, and difficulties with mathematics language and notation.

Especially in Abstract Algebra, Hart [9] describes a study of 29 college mathematics majors, taking different Abstract Algebra courses from beginning undergraduate to beginning graduate, that were asked to write six standard Abstract Algebra proofs, in 15 minute or less for each proof. On the basis of their performance on three criterion proofs, students were classified into four levels of conceptual understanding. Analysis of errors made, processes used, correctness of proofs, and student assessment of tasks suggested that the journey from novice to expert in a content domain may be an irregular and unstable developmental process, rather than the dichotomy often assumed in the literature.

Selden and Selden [1] describe errors and misconceptions exhibited by college students as they attempted to write proofs in a junior-level Abstract Algebra course. The Abstract Algebra courses used for the study were those taught by the investigators at several different universities. Seventeen errors were documented and analyzed. The errors were classified into two ways: (1) according to whether or not they were misconception-based, and (2) according to their logical characteristics. In discussing their results, the investigator raised some questions, such as the completeness of their lists, the sources of the errors, and how they might be prevented. They also suggest that students' reasoning abilities could be improved if lower-division mathematics courses would include instruction on creating and validating algorithms, rather than just implementing algorithms.

Abstract Algebra is a generalization of school algebra in which the variables can represent various mathematical object, including numbers, vectors, matrices, functions, transformations, and permutations, in which the expressions and equations are formed through operations that make sense for particular objects: addition and multiplication for matrices, composition for functions, and so on. Abstract Algebra consists of axiomatic theories that provide opportunities to consider many different mathematical systems as being special cases of the same abstract structure.

According to Findel [4], proof plays a central role in the learning of Abstract Algebra. A course in Abstract Algebra is the place where students might extract common features from many mathematical systems that they have used in previous mathematics courses, such as calculus, linear algebra, and school algebra. Students have the opportunities to develop deeper understanding of concepts such as identity, inverse, equivalence, and function. For example, what is shared, by the identity for multiplication of real numbers, the identity matrix, and the identity function? 
What is the common idea behind the inverse of function, the inverse of a matrix, and the multiplicative inverse of a number? In Abstract Algebra, students can also learn about the importance of precise language in mathematics and about the role of definitions in supporting such precision. Mathematics is also about noticing when things are the same and being able to describe how they are different. In Abstract Algebra, this naive notion of "sameness" becomes formalized in the concept of isomorphism.

The learning of many university level mathematical topics has been investigated using the APOS (Action-Process-Object-Schema) theory and an instructional sequences have been designed to reflect it. This study focuses on the effect of instruction based upon APOS theory to improve students' ability to prove in elementary Abstract Algebra. Specifically, this study was designed to address the following research question and to test the corresponding directional research hypothesis:

\section{Research Question:}

What is the effect of the APOS theory paradigm on the ability to prove in Elementary Abstract Algebra?

\section{Research Hypothesis:}

The ability to prove of students who have been involved in APOS theory instruction is statistically greater than the ability to prove of students who have been involved in only teacher-centered, traditional learning.

\section{LITERATURE REVIEW}

This section is intended to provide the reader with reference definitions and basic ideas for the following sections.

\subsection{APOS Theory and Related Research}

The work of Dubinsky and his colleagues is based on a well-articulated framework for research and curriculum development in undergraduate mathematics education [15], which grows largely from Dubinsky's elaboration of Piaget's notion of reflective abstraction [5]. The core of the framework is the theoretical perspective that all mathematical conceptions can be understood as actions, processes, object, or schemas (hence the acronym APOS). It is important to keep in mind that the theoretical perspective provides ways to categorize student's thinking about mathematical concepts, not categories for concepts themselves. Thus, one student may have an action conception of coset and another a process conception. The categories are roughly developmental, with each new conception requiring new mental constructions.

According to Dubinsky's theory, an action conception is different from process conception in that in the former, the student is particularly focused on going 
through specific procedural steps and is unable to talk clearly about one of steps until all the previous steps have been carried out. An action conception can become a process conception through a mental construction called interiorization. Then, the student can think about the result of the process without actually having done it and, in particular, can imagine reversing the process. A student who has an object conception of a mathematical idea can imagine it as a totality and, in particular, can act on it with higher-level actions or processes. Processes can be encapsulated into objects, and it is sometimes usefully that the student be able to de-encapsulate an object to focus on the underlying process. Schemas are coordinated collections of actions, processes, objects, and other schemas, which can themselves be encapsulated into objects.

Dubinsky's research and development framework consists of three activities: theoretical analysis, design and implementation of instruction, and observation and evaluation of the implemented instruction. The theoretical analysis describes the actions, processes, objects, and schemas that students might construct in order to develop an understanding of the target concepts. Instructional activities are designed specifically to help students make the constructions identified in the theoretical analysis, and typically include computer activities using the programming language ISETL (Interactive Set Language), whose syntax closely resembles mathematical notation. Evaluation consists largely of interviews and written exams to determine to what extent students made the desired constructions. The framework is cyclical in that observation and evaluation inform revisions in the theoretical perspective, which informs subsequent instructional design, and so on. The research papers primarily report the result of a particular implementation, focusing primarily on characterizing the action, process, and object conceptions of student, reporting the number of students in each category, and sometimes, comparing result with classes that had received traditional instruction.

On the learning of Abstract Algebra, the evaluation of the first round of curriculum development is reported in a research article (see [6]) and the resulting second version of the curriculum has been published (see [8]). Dubinsky et al. [6] conclude, not surprisingly, that many of the concepts, especially coset and quotient group, seem quite difficult for students, and they offer some explanations. They discuss a number of cognitive obstacles that are common among beginning Abstract Algebra students. Regarding the group concept, the idea of an abstract binary operation poses a significant obstacle for students, who often think of a group as a set and ignore the operation. Student are often unable to correctly answer questions about cosets and quotients of non-cyclic groups, and they often confuse normality with commutativity. Although some of students can perform the calculations required in listing the elements of a coset, they have difficulties in thinking of cosets as objects that can themselves be manipulated. It may seem obvious that a set is an object, but sets are often described by a process that list all elements or that would eventually list any element. In this way a set is a process. A set is not a full-fledged object in the mind of the student until the student can imagine a set as an element of another set (not just as a subset of another set). The researchers iso- 
late certain prerequisites to succeed in Abstract Algebra, including understanding of functions as both processes and objects.

This research has been criticized by Burn [3], who characterizes Dubinsky's research on learning fundamental concepts of group theory (see [6]) as a report of a novel teaching procedure using the computer and particular activities. He suggests that the fundamental concept of group theory may be not group, subgroup, coset, and normality, but rather closure, associative, identity, inverse, function, and set. Burn further points out that some of the interview excerpts that were regarded as misconceptions may actually reveal insight on the part of the student (e.g., closure is enough to determine whether a subset of finite group is a subgroup). Furthermore, quotient groups are quite easy to see in some situation (e.g., even and odd integers, rotations and reflections in the transformations of the plane). It should not be surprising, Burn suggests, that concepts in Abstract Algebra can be described in the language of set and function. Finally, he proposes that automorphism (especially permutations and symmetries) may be more profitably viewed as the fundamental concept of group theory, rather than group, subgroup, coset, and normality.

Dubinsky et al. [7] respond by reaffirming that their previous article is not a report of a novel teaching procedure but an attempt to contribute to knowledge of how student understand certain concepts in group theory. Regarding Burns' unsupported claims about the ease with which students might understand certain instances of quotient group or permutation, they suggest that Burn conduct a study and report on it.

The second iteration of research and curriculum development using the APOS framework to study the learning of Abstract Algebra is reported in a collection of articles (see [16] \& [17]). The general conclusion of these articles is that the authors' initial epistemological analyses of various topics are supported by the data, in the sense that the analyses describe the important processes, objects, and schemas that students need to construct in order to learn those topics. The authors then typically offer refinements of the epistemological analysies and later offer pedagogical suggestions. Some specific conclusions include the suggestion that the crucial idea in calculating a quotient group may be constructing the binary operation, the importance of being able to choose appropriately between two binary operations defined on a set (e.g., multiplication and addition), and specific misconceptions such as the fact that some students believe that $\mathbb{Z}_{n}$ is subgroup of $\mathbb{Z}$.

\subsection{The Ability to Prove}

According to Selden \& Selden [2], the ability to prove consists of ability in proof construction and validation of proofs. Validation normally emphasizes proceeding linearly from the beginning to the end of a written proof, possibly repeated several times. This linear order is unlikely to occur in proof construction. Given a theorem to prove, one must often attend not only to the beginning but also to the end of a proof before developing the middle. In addition, many proofs have a hierarchical structure based on sub proofs and sub constructions that emerge during the process of proof construction. Validation might include asking and answering 
questions, assenting to claims, constructing sub proofs, remembering or finding and interpreting other theorems and definitions, complying with instructions (e.g., to consider or name something), and conscious (but probably nonverbal) feelings of rightness or wrongness. Proof validation can also include production of new text (someone constructs modification of a written argument) that might include additional calculations, expansions of definitions, or constructions of sub-proofs. Toward the end of validation, in an the effort to capture the essence of the argument in a single train of thought, contractions of the argument might be undertaken.

Validation and proof construction also differ in important respects. Proof construction is much more like mathematical problem solving, in the sense of Schoenfeld, than is validation [2]. Generally, constructing a proof requires that more diverse ideas come to mind at the "right time" than validating it does.

\section{METHODOLOGY}

\subsection{Research Design}

In order to examine the effect of APOS theory in a realistic school setting, this study employed a quasi-experimental nonrandomized pretest-posttest control group design. This design was selected because it was not possible to randomly assign students to the experimental treatment (receiving APOS theory instruction) and to the control treatment (receiving traditional instruction). Instead, all students in a particular class have to receive one treatment or the other. In addition, this design was employed because the study was intended to establish a cause-effect relationship through the manipulation of treatment variable. Moreover, the use of a control group was possible, thus allowing gain differences to be attributed to treatment differences.

The distinguishing features of the nonrandomized pretest-posttest control group design are as follows: (1) the subjects in both control and experimental groups were pre-tested; (2) the experimental group was taught using APOS theory approach while the control group was taught using the teacher-centered traditional approach; and (3) the two groups were then post-tested. The following is the research paradigm that was utilized in this study.

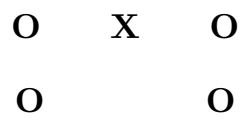

In this study, the independent variables were the method of learning (APOS and TRAD). The dependent variable was the ability to prove.

\subsection{Subjects}

The subjects for our study were 180 student at Department of Mathematics UNAND and Department of Mathematics Education UNP who had taken (but not yet passed) or were taking a first course in Abstract Algebra of the course during 
February-May 2005/2006. Of these 180 students, 90 students were taught using APOS theory instruction, and the rest were taught using traditional mathematics instruction.

\subsection{Instructional Treatments}

Each class received two 150-minute periods per week (for five week) in Abstract Algebra instruction. The students in control group were taught using traditional instruction in mathematics, that is: (1) presentation of new materials on Abstract Algebra, (2) examples or non-examples and proofs of lemmas or theorems were given, (3) questions asked were designed to confirm definitions, examples, and proofs which have been given, (4) students solved the exercises and problems given in the text books individually and each product was subsequently checked for accuracy, and finally (5) assignments or homework was given. The course uses a textbook that was written by Herstein (see [11]).

Students in the experimental group, by contrast, were taught using APOS theory instruction. The overall structure of the experimental course was based on the ACE teaching cycle utilizing both computers and cooperative groups. Students were grouped permanently consists of three or four members each, and the majority of course work was completed in groups. Material was broken into topical sections, each of which ran for approximately one week. Two and a half hours of class sessions per week were spent in computer laboratory, and two and a half hours of class sessions per week were held in a classroom with no computers. In the computer laboratory, students completed computer activities using the mathematical programming language ISETL. In order to stimulate reflection, the computer activities usually dealt with concepts that had not been formally studied in class. These concepts were then discussed in the successive class meetings. To encourage further exploration of the concepts, students were assigned homework to be completed outside class; both computer exercises and traditional exercises were included in the assignments. The course uses a textbook that was written explicitly to support this pedagogical approach (see [8]). Here is a small sample for APOS theory approach to Abstract Algebra course (getting acquainted with groups and its properties).

Activities in the computer laboratory:

(1) Students write some ISETL functions (func) which would help students to construct the notion of closed, associative, identity element, inverse of an element, commutative, and groups:

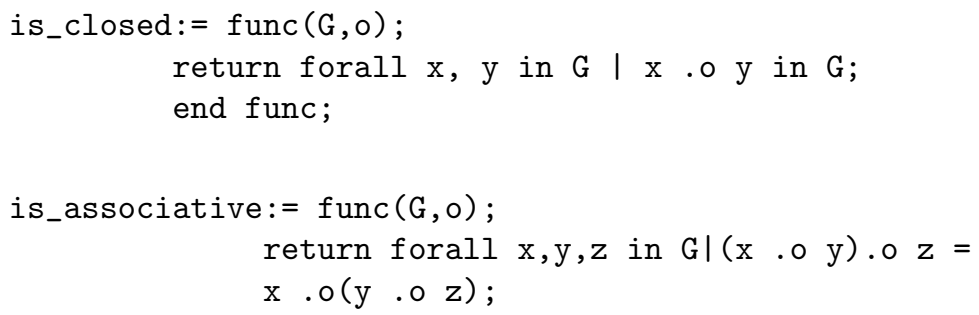




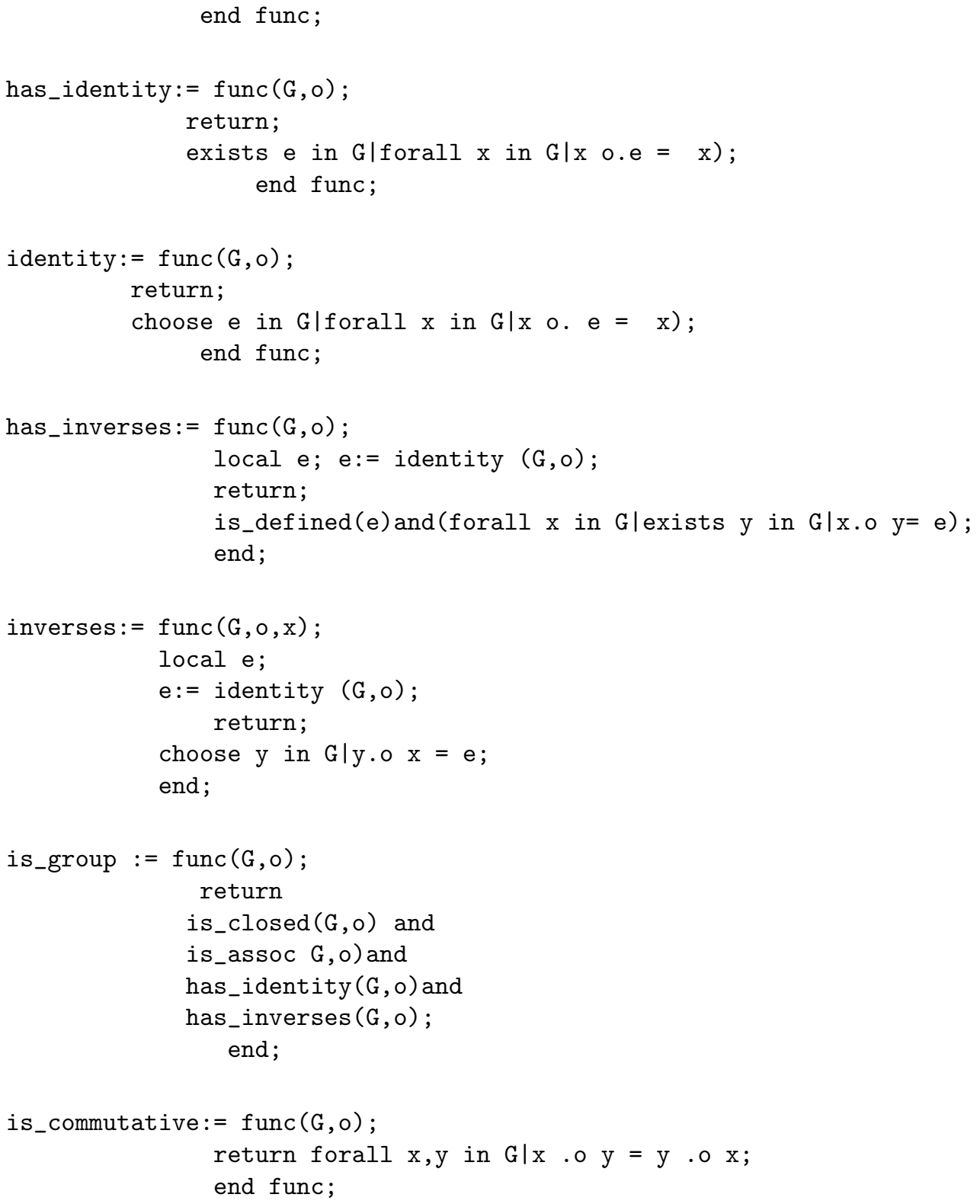

(2) Students applying those ISETL function filled Table 1, Table 2a, and Table $2 b$.

(3) The instructor would guide students (students' team) to apply those ISETL functions. 
Table 1: Some Example and Non Example of Groups

\begin{tabular}{|c|c|c|c|c|c|c|}
\hline Sets & $\begin{array}{c}\text { Biner } \\
\text { Op. }\end{array}$ & $\begin{array}{c}\text { Is } \\
\text { Associative? } \\
(\mathrm{Y} / \mathrm{N})\end{array}$ & $\begin{array}{c}\text { Is } \\
\text { Closed? } \\
(\mathrm{Y} / \mathrm{N})\end{array}$ & $\begin{array}{c}\text { Has } \\
\text { Inverses? } \\
(\mathrm{Y} / \mathrm{N})\end{array}$ & $\begin{array}{c}\text { Has } \\
\text { Identity? } \\
(\mathrm{Y} / \mathrm{N})\end{array}$ & $\begin{array}{c}\text { Is } \\
\text { Group? } \\
(\mathrm{Y} / \mathrm{N})\end{array}$ \\
\hline \hline $\mathbb{Z}_{20}$ & $+(\bmod 20)$ & & & & & \\
\hline$S_{3}$ & $\begin{array}{c}\text { ○(composition } \\
\text { of func. })\end{array}$ & & & & & \\
\hline $\mathbb{Z}_{20}-\{0\}$ & $\bullet(\bmod 5)$ & & & & & \\
\hline$S_{4}$ & $\begin{array}{c}\text { o (composition } \\
\text { of func. })\end{array}$ & & & & & \\
\hline $\mathbb{Z}_{5}$ & $+(\bmod 5)$ & & & & & \\
\hline $\mathbb{Z}_{5}$ & $\bullet(\bmod 5)$ & & & & & \\
\hline $\mathbb{Z}_{5}-\{0\}$ & $\bullet(\bmod 5)$ & & & & & \\
\hline
\end{tabular}

Table 2a: Some Fact about Properties of Groups

\begin{tabular}{|c|c|c|c|c|c|}
\hline Groups & $\begin{array}{c}\text { Invers } \\
(a)\end{array}$ & $\begin{array}{c}\text { Invers } \\
(b)\end{array}$ & $\begin{array}{c}\text { Invers } \\
(a * b)\end{array}$ & $\begin{array}{c}\text { Invers }(a * b)= \\
\text { Invers }(a) * \\
\text { Invers }(b) ? \\
(\mathrm{Y} / \mathrm{N})\end{array}$ & $\begin{array}{c}\text { Invers }(a * b)= \\
\text { Invers }(b) * \\
\text { Invers }(a) ? \\
(\mathrm{Y} / \mathrm{N})\end{array}$ \\
\hline \hline $\begin{array}{c}\left(\mathbb{Z}_{20},+_{\text {mod } 20}\right) \\
a=15, b=17\end{array}$ & & & & & \\
\hline $\begin{array}{c}\left(S_{3}, \circ\right) \\
a=[3,2,1] \\
b=[2,1,3]\end{array}$ & & & & & \\
\hline $\begin{array}{c}\left.\mathbb{Z}_{5}-\{0\}, \bullet \text { mod } 5\right) \\
a=3, b=4\end{array}$ & & & & & \\
\hline $\begin{array}{c}\left(S_{4}, \circ\right) \\
a=[4,3,2,1], \\
b=[4,2,1,3]\end{array}$ & & & & & \\
\hline
\end{tabular}

Table 2b: Some Fact about Properties of Groups

\begin{tabular}{|c|c|c|c|}
\hline Sets & Biner Op. & $\begin{array}{l}\text { Is group? } \\
(\mathrm{Y} / \mathrm{N})\end{array}$ & $\begin{array}{l}\text { if } a \neq b \text { then } c * a \neq c * b \\
\qquad(\mathrm{Y} / \mathrm{N})\end{array}$ \\
\hline $\begin{array}{c}\mathbb{Z}_{20} \\
a=3, b=5, c=7\end{array}$ & $+(\bmod 20)$ & & \\
\hline $\begin{array}{c}\mathbb{Z}_{20} \\
a=4, b=8, c=5\end{array}$ & - $(\bmod 20)$ & & \\
\hline $\begin{aligned} & \mathbb{Z}_{20}-\{0\} \\
& a=3, b=7, c=9\end{aligned}$ & - $(\bmod 20)$ & & \\
\hline $\begin{array}{c}S_{4} \\
a=[4,3,2,1], b= \\
{[3,4,2,1], \quad c=[2,4,3,1]}\end{array}$ & $\begin{array}{l} \\
\text { (Composition } \\
\text { of func.) }\end{array}$ & & \\
\hline $\begin{array}{c}\mathbb{Z}_{5}-\{0\} \\
a=2, b=3, c=4\end{array}$ & - $(\bmod 5)$ & & \\
\hline
\end{tabular}


Classroom Interaction/Classroom Discussion:

The instructor would give some exposition on those ISETL functions which was being studied and summarize the result of student's activities (based on Table 1, Table 2a, and Table 2b). During class, based on Table 1, Table 2a, and Table 2b, the instructor would guide students to state definition of groups and state theorems. Occasionally the instructor would prove some theorems. However, students would mostly prove the theorems. Students were not told how to solve problems. They learned that, before a question was probed, serious thought should be given to the issue. Every effort should be made to resolve the issue before seeking wisdom from instructor. This process would usually involve significant interaction within the students' team and some time with other teams. When a question was put to the instructor, it was often greeted with a question (a question that leads students to find out what he/she really is trying to do).

Exercises:

The instructor would give some exercises for students to work on in teams. Most of them are expected to be completed outside of class. The purpose of the exercises is for students to reinforce the idea (groups and its properties) they have constructed, to use the mathematics they have learned and to begin thinking occasionally about situations that would be studied later. For example: (1) Prove that the set of $\mathbb{Q}-\{0\}$ with the binary operation $\Delta$, where $\Delta$ is defined by: $x \Delta y=(x \cdot y) / 2(\cdot$ is the standard multiplication of rational numbers), is a group. (2) Find a subset $H$ of $\mathbb{Q}-\{0\}$ such that $\mathrm{H}$ is a group with the binary operation $\triangle$.

The instructor would: (1) give sufficient time for students to develop their own solutions, (2) write on the blackboard the arguments presented by students, without alteration, repeating aloud what may have been said too softly, (3) invite students to give some comments, (4) guide students to obtain the right solution.

\subsection{Instrumentation}

Two test instruments (Test I and Test II) were used. Test I and Test II consist of, respectively, six and five carefully selected proofs from Elementary Abstract Algebra. These proofs were selected in order to (a) reflect an understanding of Elementary Abstract Algebra, (b) be the representative of basic types of proof in Abstract Algebra, (c) be done in 20 minutes each by students with some understanding of the definition of group, subgroup, commutative group, normal subgroup, and homomorphism, (d) be complex enough to generate interesting data concerning processes and errors from students with a wide range of conceptual understanding.

On the issue of validity (the degree to which a test measures what it purports to measure), both test had been designed with the purpose of testing the extent to which each student had mastered the mathematical skills stipulated in the instructional objectives. This also implies that both tests have the content validity based on the fact that the test items adequately represented the subject matter of the mathematics and mathematics education curriculum.

Two weeks prior to the course began, every student in each class, control or 
experimental took the two hour pre-test for Test I and the two hour pre-test for Test II, at the end of the 3-week instruction, they took the two hour post-test for Test I, and then at the end of 5-week instruction, they took the two hour post-test for Test II, so we have four measurements (scores) for each student (180 students). The supervision of the testing was done by the respective classroom's lecturers according to the normal time table of the course.

\subsection{Data Analysis}

Data were gathered on correctness of the proofs; there were $720(2 \times 90 \mathrm{x}$ 4) answer sheets which must be assessed using a method adapted from Malone et al. (see [9]), where each proof was graded on a scale of 0 to 4 as follows: 0 (noncommencement); 1 (approach made); 2 (substantial progress); 3 (result achieved with only minor errors); 4 (completion). For example, there is a problem in Test I as follows: If $\mathrm{G}$ is a group in with $(a * b)^{2}=a^{2} * b^{2}$ for all a and $\mathrm{b}$ in $\mathrm{G}$, show that $\mathrm{G}$ is commutative group. Some students answered that problem as follows: Let $\mathrm{G}$ be a group such that for all a and $\mathrm{b}$ in $\mathrm{G},(a * b)^{2}=a^{2} * b^{2}$. To show $\mathrm{G}$ is commutative means, for all $\mathrm{a}$ and $\mathrm{b}$ in $\mathrm{G}$, it must be proved that $a * b=b * a$.

$$
\begin{gathered}
\text { Since }(a * b)^{2}=a^{2} * b^{2}, \text { then } \\
\text { square } \operatorname{root}\left[(a * b)^{2}\right]=\text { square } \operatorname{root}\left[a^{2} * b^{2}\right], \text { or } \\
a * b=b * a .
\end{gathered}
$$

In this case, he/she has known: (1) what must be shown, and (2) the premise to start the proof process. But, definitely there was an error in step 2, therefore he/she showed that he/she has not comprehended the concept of $n$ power of group element, so for this problem he/she carried a score of 2 .

Analysis of variance (one way ANOVA) was used as the primary statistical analysis. The essential result from the computation are the F-ratio and probability (p) value for the group main effect. The level of significance for the hypothesis in this study was set at .05 level $(\mathrm{p}<.05)$.

\section{RESULTS AND DISCUSSION}

\subsection{Results}

For every student (of 180 students) we have: (1) gain scores for Test I (gains Test I = post-test Test I - pre-test Test I), (2) gain scores for Test II (gains Test II = post-test Test II - pre-test Test II), (3) gain scores for Test I \& II (gains Test I $\&$ II = gains Test I + gains Test II). The statistical package used for the computer analysis of all data was SPSS12. The means and standard deviations of gains Test I, gains Test II, and gains Test I \& II are presented in Table 3. 
Table 3: Means and Standard Deviations for Gains Test I, Gains Test II, and Gains Test I \& II

\begin{tabular}{|l|c|cc|cc|cr|}
\hline Instruction & N & \multicolumn{2}{|c|}{ Gains Test I } & \multicolumn{2}{|c|}{ Gains Test II } & \multicolumn{2}{|c|}{ Gains Test I and II } \\
& & $\bar{X}$ & SD & $\bar{X}$ & SD & $\bar{X}$ & SD \\
\hline \hline APOS & 90 & 11.72 & 4.04 & 11.22 & 3.25 & 22.94 & 6.48 \\
\hline TRAD & 90 & 10.56 & 4.22 & 9.12 & 3.76 & 19.68 & 7.51 \\
\hline $\begin{array}{l}\text { Difference in } \\
\text { Gains between } \\
\text { APOS and TRAD }\end{array}$ & & 1.16 & & 2.10 & & 3.26 & \\
\hline
\end{tabular}

Maximum score for Test I and Test II were 24 and 20 respectively.

The gains means for Test I, Test II, and Test I \& II have the difference of $1.16,2.1$, and 3.26 respectively (i.e. subtract 10.56 from 11.72 , subtract 9.12 from 11.22, and subtract 19.68 from 22.94), indicating a remarkable improvement in the achievement gains of the students who had been involved in the APOS theory instruction, because Abstract Algebra is difficult subject for students. Table 3 also shows that the students who had been involved in the APOS theory instruction have smaller standard deviation for the gains on Test I, Test II, and Test I \& II than students who had been involved in traditional approach, indicating that students in experimental group has less variance score than students in control group (all student getting score 0 for pre-test Test I and pre-test Test II, so gains Test I = score Test I and gains Test II = score Test II).

The summary results of the one way analysis of variance are presented in Table 4. The alpha level for the design was set at $p<.05$.

Table 4: The Result of One Way Analysis of Variance

\begin{tabular}{|c|c|}
\hline \multicolumn{2}{|c|}{ Gain Test I \& Test II } \\
\hline \hline $\mathrm{F}$ & $\mathrm{P}$ \\
\hline 9.297 & .003 \\
\hline
\end{tabular}

The results of the one way analysis of variance yielded a significant main effect of instruction for the gains on Test II and Test I \& II $(p<.05)$, signifying that APOS theory approach definitely did has an effect on the ability to prove in comparison to the traditional approach.

Students' mean gain scores were plotted in Figure 1. Figure 1 shows that in both tests (Test I and Test II), for each test item, the mean of the gains for students in control group is less than for students in experimental group, indicating that students in experimental group have better understanding on proof in abstract algebra (i.e. proof construction and validation of proof).

\subsection{Discussion}

Not surprisingly instruction with APOS theory is better than traditional instruction in improving proving ability in Abstract Algebra. Theoretically, APOS 


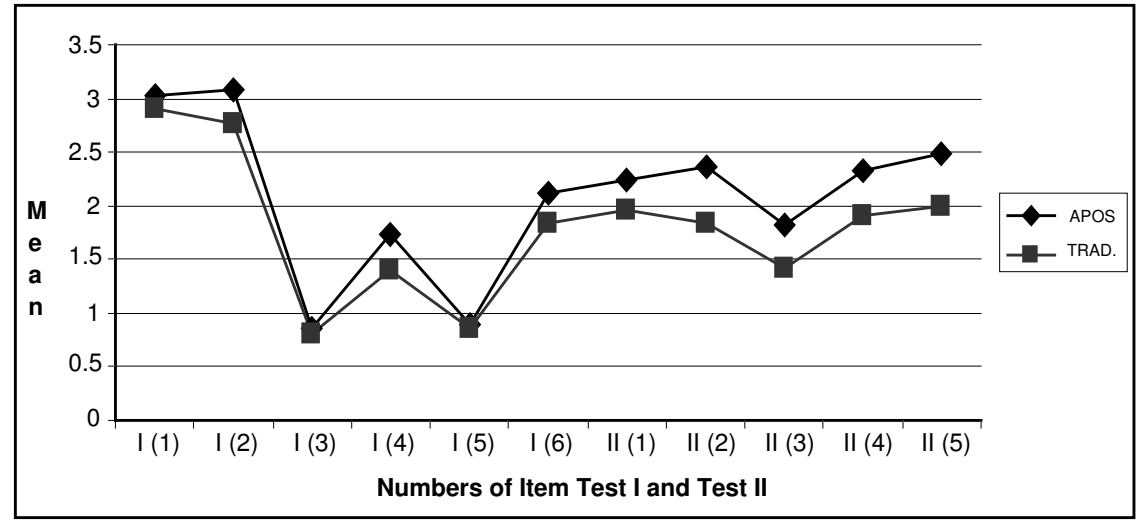

Figure 1: Plot of the mean of the gains for each test item

theory based instruction has some advantages compared to the traditional one, as shown in Table 5.

Table 5: Characteristic Differences of APOS Theory and Traditional Approach

\begin{tabular}{|c|l|l|}
\hline No. & \multicolumn{1}{|c|}{ APOS Theory Approach } & \multicolumn{1}{c|}{ Traditional Approach } \\
\hline \hline 1 & $\begin{array}{l}\text { Topics are designed regarding the } \\
\text { mental construction steps: actions, } \\
\text { processes, objects, and schemas. Stu- } \\
\text { dents are involved actively in learning. } \\
\text { Mathematics ideas (definitions, lem- } \\
\text { mas, and theorems) are discovered by } \\
\text { students through fact findings in the } \\
\text { laboratory activities. }\end{array}$ & $\begin{array}{l}\text { Topics are not designed specifically, } \\
\text { tures' class notes. Students receive } \\
\text { information passively. Mathematics } \\
\text { ideas are given in a ready-made fash- } \\
\text { ion. }\end{array}$ \\
\hline 2 & $\begin{array}{l}\text { The role of lecturer/instructor as a fa- } \\
\text { cilitator, i.e. supports guidance to stu- } \\
\text { dents, group or entire class through } \\
\text { scaffolding, e.g. questioning, giving } \\
\text { hints. }\end{array}$ & $\begin{array}{l}\text { The role of lecturer/instructor as } \\
\text { a knowledge transformer, i.e. the } \\
\text { lecturer/instructor directly explains } \\
\text { mathematics ideas. }\end{array}$ \\
\hline 3 & $\begin{array}{l}\text { There is multi-direction interaction } \\
\text { among students, as well as students } \\
\text { and lecturer. Students learn from } \\
\text { peers through work group, discussion. }\end{array}$ & $\begin{array}{l}\text { One or two way interaction involving } \\
\text { teacher. }\end{array}$ \\
\hline
\end{tabular}




\section{CONCLUSIONS}

Findings obtained from the one way analysis of variance $(\mathrm{F}=9.297, \mathrm{p}<.05)$ provide evidence to conclude that the directional research hypothesis is accepted. The interpretation would be: statistically, the ability to prove of students who have been involved in APOS theory instruction is significantly greater than the ability to prove of students who have involved in only teacher-centered traditional learning.

To implement the new instructional method (APOS), clearly students need time to adjust with an innovative approach to learning Abstract Algebra characterized by collaborative learning and special computer activities, thus the effect of APOS theory instruction in proving ability do not immediately occurs.

APOS theory approach to teaching Abstract Algebra has some advantages for student: active involvement (social interaction), opportunities to communicate mathematically, informal classroom atmosphere, freedom to ask questions, closer student-teacher relationship, opportunities to pursue challenging mathematical situation, and the instructor continuously attends to students' thinking in order to access their individual (and communal) learning capacities with respect to the task at hand, where all of these would influence student's ability to prove.

\section{IMPLICATION FOR PRACTICE}

The findings of this study suggest that the use of APOS theory instruction may benefit Indonesian students in the development of Abstract Algebra concepts in particular and mathematical concepts in general. APOS theory is still relatively new in Indonesia and more information about the impact of APOS theory on Indonesian students is very much needed. This study contributes a drop in the yetto-be-filled ocean of APOS theory instruction in Indonesia and sets the precedence in encouraging Indonesian educators to capitalize on the strength and effectiveness of APOS theory in our mission to realize our vision in education at university level.

Acknowledgement. The author wishes to thank the referee for his/her suggestions.

\section{REFERENCES}

1. A. Selden And J. Selden, Errors and Misconceptions in College Level Theorem Proving, Unpublished Technical Report, Tennessee Technological University, Cookeville, 2003.

2. A. Selden And J. Selden, "Validations of proof considered as texts: can undergraduates tell whether an argument proves a theorem?", Journal for Research in Mathematics Education 34 (2003), 4-36. 
3. B. BuRn, "What are the fundamental concept of group theory?", Educational Studies in Mathematics 31 (1996), 371-377.

4. B.R. FindeL, Learning and Understanding in Abstract Algebra, Unpublished Dissertation, University of New Hampshire, USA, 2001.

5. E. Dubinsky and D. TAll, "Advanced Mathematical Thinking and Computer", in D. Tall (ed.), Advanced Mathematics Thinking, Kluwer Academic Publishers, Dordrecht, 1991.

6. E. Dubinsky, J. Dautermann, U. Leron, and R. Zazkis, "On learning fundamental concepts of group theory", Educational Studies in Mathematics 27 (1994), 267-305.

7. E. Dubinsky, J. Dautermann, U. Leron, and R. Zazkis, "A reaction to Burn's what are the fundamental concept of group theory?". Educational Studies in Mathematics 34 (1997), 249-253.

8. E. Dubinsky And U. Leron, Learning Abstract Algebra with ISETL, Springer-Verlag, New York, 1994.

9. E.W. HART, "A Conceptual Analysis of The Proof-Writing Performance of Expert and Novice Students in Elementary Group Theory", in J. J. Kaput and E. Dubinsky (ed.), Research Issues in Undergraduate Mathematics learning. American Mathematical Society ,Washington DC, 1994.

10. G. Hanna And N. Jahnke, "Proof and Proving". in A. J. Bishop et al. (ed.), International Handbook of Mathematics Education. Kluwer Academic Publishers, Dordrecht, 1996.

11. I.N. Herstein, Topics in Algebra, John Wiley \& Sons, New York, 1975.

12. J. Hiebert, AND T.P. CARPEnter, "Learning and Teaching with Understanding", in D.A Grouws (Ed.), Handbook of Research on Mathematics Teaching and Learning: A Project of the National Council of Teachers of Mathematics, Macmillan, New York, 1992.

13. K. Jones, "The student experience of mathematical proof at university level". Internat. J. Math. Ed. Sci. Tech. 13 (2000), 53-60.

14. L.J. KwoEn, "Philosophical perspective on proof in mathematics education", Philosophy of Mathematics Education Journal, 16 (2002).

15. M. Asiala, A. Brown, D.J.Devries, E. Dubinsky, D. Mathews, and K. Thomas, "A Framework for Research and Curriculum Development in Undergraduate Mathematics Education", in E. Dubinsky et al. (ed.), Reading in: Cooperative Learning for Undergraduate Mathematics, The Mathematical Association of America, Washington DC, 1997.

16. M. Asiala, E. Dubinsky, A. Brown, D. Mathews, S. Morics, and A. Oktac, "The development of student understanding of coset, normality, and quotient groups", Journal of Mathematical Behavior 16 (1997), 241-309.

17. M. Asiala, A. Brown, J. Kleiman, and D. Mathews, "The Development of student's understanding of permutations and symmetries", International Journal of Computer for Mathematical Learning 3 (1998), 13-43.

18. R.C. Moore, "Making the transition to formal proof", Educational Studies in Mathematics 27 (1994), 249-266. 
19. SABRI, Prospective Secondary School Teachers' Conceptions of Mathematical Proof in Indonesia,. Unpublished Thesis, Curtin University of Technology, Perth, 2003.

20. W.D. MARKEL, "The role of proof in mathematics education", School Science and Mathematics 94 (1994), 291-295.

I Made Arnawa: Department of Mathematics UNAND PADANG - Indonesia. E-mail: arnaw@fmipa.unand.ac.id.

UtARI SUmARnO: Department of Mathematics Education UPI BANDUNG - Indonesia.

Bana Kartasasmita: Study Program of Mathematics, Jl. Ganesa 10 Bandung 40132, Institut Teknologi Bandung - Indonesia.

Edy Tri Baskoro: Study Program of Mathematics, Jl. Ganesa 10 Bandung 40132, Institut Teknologi Bandung - Indonesia. 